Article

\title{
Three-Dimensional Characterization of Hardened Paste of Hydrated Tricalcium Silicate by Serial Block-Face Scanning Electron Microscopy
}

\author{
Yongjuan Zhao ${ }^{1}$, Xianping Liu ${ }^{1,2, *}$, Bo Chen ${ }^{1,2,3, *}$, Fei Yang ${ }^{1}$, Yongming Zhang ${ }^{1,2}$, \\ Peiming Wang ${ }^{1}$ and Ian Robinson ${ }^{1,3,4}$ \\ 1 School of Materials Science and Engineering, Tongji University, Shanghai 201804, China; \\ 1730602@tongji.edu.cn (Y.Z.); 1610413@tongji.edu.cn (F.Y.); zym126@tongji.edu.cn (Y.Z.); \\ tjwpm@126.com (P.W.); i.robinson@ucl.ac.uk (I.R.) \\ 2 Key Laboratory of Advanced Civil Engineering Materials (Tongji University), Ministry of Education, \\ Shanghai 201804, China \\ 3 London Centre for Nanotechnology, University College London, London WC1H 0AH, UK \\ 4 Division of Condensed Matter Physics and Materials Science, Brookhaven National Laboratory, \\ Upton, NY 11973, USA \\ * $\quad$ Correspondence: lxp@tongji.edu.cn (X.L.); bo.chen@tongji.edu.cn (B.C.); Tel.: +86-021-3952-6230 (X.L. \& B.C.)
}

Received: 19 May 2019; Accepted: 3 June 2019; Published: 12 June 2019

\begin{abstract}
With the application of a three-dimensional (3D) characterization technique, serial block-face scanning electron microscopy (SBFSEM), the 3D microstructure of a hydrated cement monomineral, tricalcium silicate $\left(\mathrm{C}_{3} \mathrm{~S}\right)$, was measured with nanoscale resolution. The 3D morphologies of anhydrous particles, hydrated products, and capillary pores were visualized. Closed and open pores were discovered inside an anhydrous particle. The size and distribution of both the anhydrous $C_{3} S$ particles and their capillary pores were analyzed quantitatively and the porosity was determined to be $9 \%$. The distribution of pores was found to be in a good agreement with the inner and outer product model of Hu et. al., with an inner shell distance of $860 \mathrm{~nm}$. Considering the spatial resolution of the instrument and the volume of sample measured, most pores in this experiment could be characterized as capillary pores.
\end{abstract}

Keywords: tricalcium silicate $\left(\mathrm{C}_{3} \mathrm{~S}\right)$; hydration; 3D microstructure; serial block-face scanning electron microscopy (SBFSEM)

\section{Introduction}

Tricalcium silicate $\left(\mathrm{C}_{3} \mathrm{~S}\right)$ [1] is the main component in Portland cement, taking up $50-70 \%$ of cement mass. The hydration reaction occurs between $\mathrm{C}_{3} \mathrm{~S}$ powder and water to form two products, calcium hydroxide $(\mathrm{CH})$ and calcium silicate hydrate $(\mathrm{C}-\mathrm{S}-\mathrm{H})[2,3]$. The early-age strength of hardened cement paste can reach about $70 \%$ degree of hydration within 28 days, which is attributed to $C_{3} S[4,5]$. For this reason, the hydration of $\mathrm{C}_{3} \mathrm{~S}$ has been investigated for several decades [6] and the hydration mechanism is well understood. A variety of techniques have been developed to reveal the influence of material components and microstructure on macro-scale performance and hydration mechanism. Such visualization methods as scanning electron microscopy (SEM) [7-11], transmission electron microscopy (TEM) [12-14], atomic force microscopy (AFM) [15,16], and various newly-developed three-dimensional(3D) visualization techniques such as $\mathrm{X}$-ray computed tomography $(\mathrm{CT})$ have played important roles [2,17-21].

Three-dimensional visualization techniques have great advantages in the study of the microstructure of hardened cement pastes, compared with other traditional techniques. For example, 
while X-ray diffraction (XRD) $[7,22-24]$ and thermal analysis $[25,26]$ can be used to analyze the average chemical components and hydration degree of a whole sample, small angle scattering (SAS) techniques, including small angle X-ray scattering (SAXS) and small angle neutron scattering (SANS) can be used to characterize the size of gel particles and gel pores [27-29], and X-ray CT can be used to analyze the 3D morphology and distribution of independent micro regions [2,30], which is essential for heterogeneous materials like cement. Compared with 2D techniques such as SEM and TEM, 3D techniques have the advantage of revealing the spatial distribution and the real morphology of irregular-shaped components. In addition, 3D visualization techniques are better than mercury intrusion porosimetry (MIP) in the investigation of pore morphology and pore connectivity [31,32], although MIP is still the traditional way to measure pores in the $1 \mathrm{~nm}$ to $1000 \mu \mathrm{m}$ size range [33].

Like X-ray CT, serial block-face scanning electron microscopy (SBFSEM) is a 3D visualization technique [34]. The concept of SBFSEM was put forward in 1981 [31], and the system of SBFSEM was well-developed by Denk et al. in 2004 [35]. While SBFSEM was developed for use in life sciences, Zankel [36] applied SBFSEM to the study of 3D microstructures of materials in 2009. SBFSEM has widespread potential applications in material science. It has been reported that SBFSEM has been used to image and analyze the 3D microstructures of internal voids, chemical compositions, crack morphology distribution, and interfacial bonding of coatings and adhesives [37,38], alloys [39,40], and zeolite [41]. As an electron microscopy-based 3D technique, SBFSEM can reach about 10-15 nm resolution in three dimensions [37].

The principle of SBFSEM sample preparation is to maintain the microstructure and composition characteristics of samples for the cutting-and-imaging measurement process, since SBFSEM is a destructive method of analysis. Due to the characteristics of the samples, they are usually embedded into epoxy resin and trimmed into a pyramid after hardening to hold the samples (and their structures) during preparation and measurement $[42,43]$.

This current work extends our previous study on $\mathrm{C}_{3} S$ powders with SBFSEM [44] to the hardened paste of hydrated $C_{3} S$. This expands the application fields of SBFSEM in inorganic, brittle, and heterogeneous materials and demonstrates $3 \mathrm{D}$ information on the nanometer scale for the microstructure of hardened cement paste. We observed the 3D morphologies of anhydrous $C_{3} S$, hydrates, and the pore structure of $\mathrm{C}_{3} \mathrm{~S}$ after $24 \mathrm{~h}$ of hydration. The pore size distributions, porosity, and diameter of the pores have been documented qualitatively.

\section{Materials and Methods}

Monoclinic $\mathrm{C}_{3} \mathrm{~S}$ was synthesized by high sintering according to the methods reported by De la Torre et al. [45] and then ground into powder before hydration. The purity of the raw material measured by powder X-ray diffraction using the Rietveld method was about $98 \%$. The synthetic $\mathrm{C}_{3} \mathrm{~S}$ was hydrated to a water to $\mathrm{C}_{3} \mathrm{~S}$ powder ratio $(\mathrm{w} / \mathrm{c})$ of 0.5 at $20^{\circ} \mathrm{C}$ for $24 \mathrm{~h}$. Because of the restriction of sample volume by SBFSEM, the hydration of $\mathrm{C}_{3} \mathrm{~S}$ was conducted in two steps. Firstly, $\mathrm{C}_{3} \mathrm{~S}$ was hydrated in a sealed plastic tube for $5 \mathrm{~h}$. Then, it was removed from the tube and broken into several smaller particles. Then, the particles continued to hydrate at $20{ }^{\circ} \mathrm{C}$ with $60 \%$ relative humidity for another $19 \mathrm{~h}$.

The hydration of the sample was then stopped by infusion with absolute ethanol. This hydration-stopped sample was then dried and embedded in epoxy resin which was cured at $60^{\circ} \mathrm{C}$ for $48 \mathrm{~h}$. The cured sample was trimmed into a frustum-pyramid shape (length of top surface $<500 \mu \mathrm{m}$, height $<1 \mathrm{~mm}$ ) using a Leica microtome (Leica Microsystem Inc., Buffalo., IL., USA) and fixed on the sample holder with superglue for $2 \mathrm{~h}$. Conductive silver adhesive was applied around the surface of the sample in order to increase its conductivity.

Backscattered electron (BSE) images of a series of cross sections of the sample were obtained with a Zeiss Sigma VP scanning electron microscope (Carl Zeiss Microscopy GmbH, Oberkochen, Germany) equipped with a Gatan "3View" in-chamber ultramicrotome (Gatan UK, Abingdon, UK). A Gatan "onpoint" backscattered electron detector (Gatan UK, Abingdon, UK) was used to acquire a series of 
images from each new section of the sample that was cut by the in-chamber ultra-microtome (Gatan UK, Abingdon, UK). Data were collected in high vacuum mode with a $1.5 \mathrm{kV}$ accelerating voltage and 2 us/pixel dwell time. An image stack with a $50 \mathrm{~nm} /$ pixel and 15nm thickness was obtained.

In order to increase the computation speed, original images of $2048 \times 2048$ pixels were binned into $1024 \times 1024$ pixels using the ImageJ 2 (Open Source software). Two image stacks obtained from the above procedure were imported separately into Avizo 9.4.0 (Thermo Fisher Scientific Inc, Waltham, MA, USA) for image processing, reconstruction, and analysis. Semi-automatic segmentation and manual segmentation were used in combination to increase the accuracy. Quantitative analysis was also done on the 3D images.

\section{Results and Discussion}

\subsection{The 3D Microstructure of Hardened Paste of Hydrated $C_{3} S$}

The BSE image of the first section of the hardened paste of $C_{3} S$ hydrated for $24 \mathrm{~h}$ is shown in Figure 1a. A 3D-rendered image obtained from 380 slices is shown in Figure 1b. According to the atomic number/Composition contrast in the BSE image of Figure 1a, the bright features are anhydrous $\mathrm{C}_{3} \mathrm{~S}$ particles, the grey features are hydrates and the dark features are pores and spaces filled by epoxy. These three features are rendered in blue, grey, and green respectively in Figure 1b. Rendered 3D images of anhydrous $\mathrm{C}_{3} \mathrm{~S}$ particles and pores, shown in Figure $1 \mathrm{c}, \mathrm{d}$, have been qualitatively and quantitatively analyzed to further understand the microstructure characteristics of hardened paste in three dimensions.

(a)

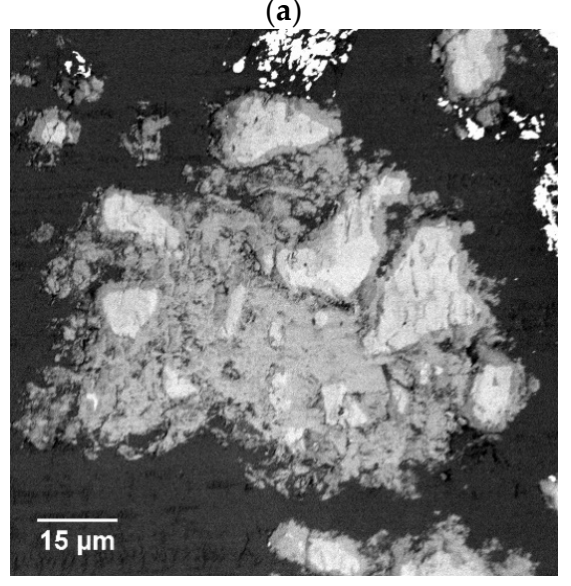

(c)

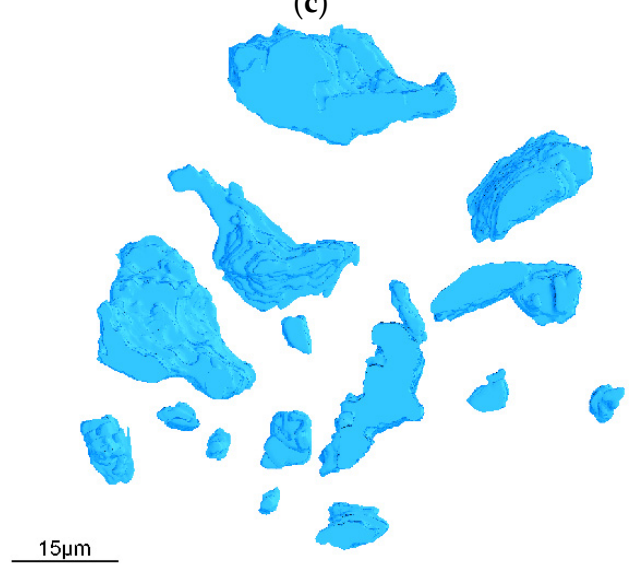

(b)

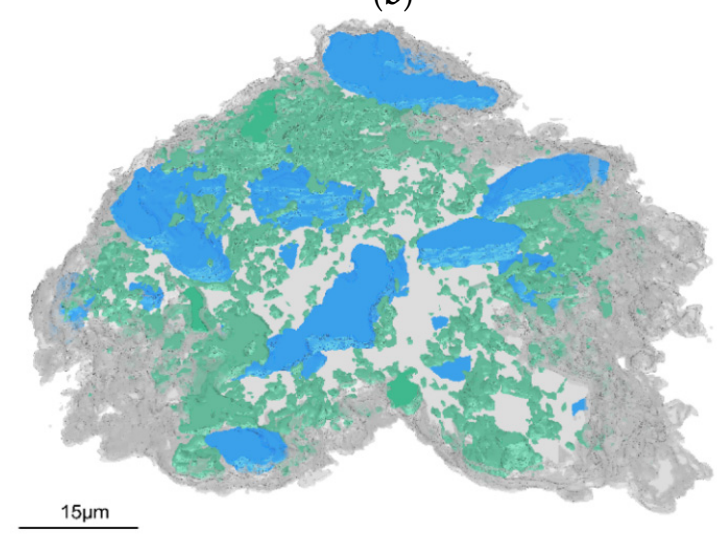

(d)

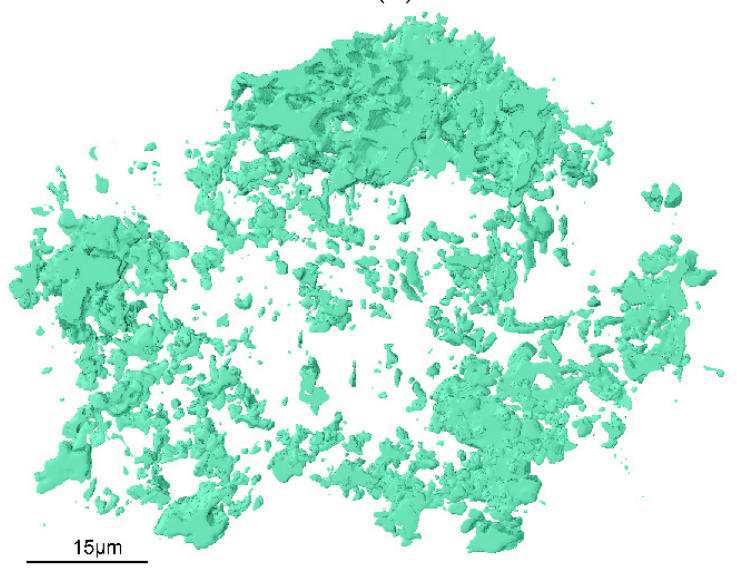

Figure 1. Two-dimensional and three-dimensional images of the hydrated $\mathrm{C}_{3} \mathrm{~S}$ : (a) the original BSE image of samples, (b) the 3D rendered image of the sample, (c) anhydrous particles, and (d) pores in the hydrated $C_{3} S$ paste. 


\subsection{Analysis of Anhydrous $C_{3} S$ Particles in the Hydrated $C_{3} S$ Paste}

\subsubsection{Morphological Parameters of Anhydrous $\mathrm{C}_{3} \mathrm{~S}$}

Figure $2 \mathrm{a}$ is a labeled $3 \mathrm{D}$ image of the segmented anhydrous $\mathrm{C}_{3} \mathrm{~S}$ particles, in which each anhydrous particle is assigned an ID number from 1 to 18. Basic 3D morphological parameters were analyzed using the "label analysis" module in Avizo to provide the volume, the area of the object boundary (labeled as 'area'), and the specific surface area, as well as the diameter of the spherical particles of the same volume (labeled "diameter") of all anhydrous particles. The analysis results are shown in Supplementary Spreadsheet S1 and in Figure $2 b$. The volume ranges from $1.26 \times 10^{6}$ to $1.3 \times 10^{9} \mathrm{~nm}^{3}$. The diameter of the anhydrous particle ranges from 2500 to $12500 \mathrm{~nm}$, calculated from the equivalent spherical diameter, which is consistent with the volume change. The area changes with the morphology, resulting in the fluctuations in the specific surface area. The general trend is that smaller particles have larger specific surface areas. It is believed that the higher the specific surface area, the higher the hydration rate of anhydrous $\mathrm{C}_{3} \mathrm{~S}$ particles due to a larger contact area between water and the particles.

(a)

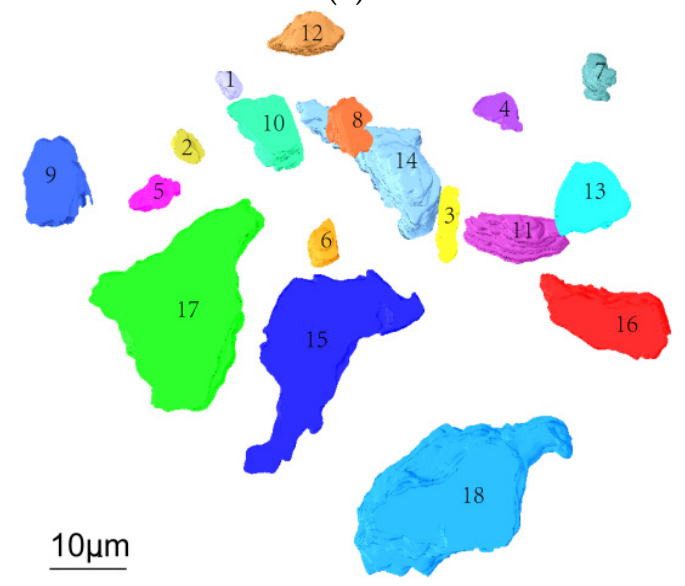

(b)

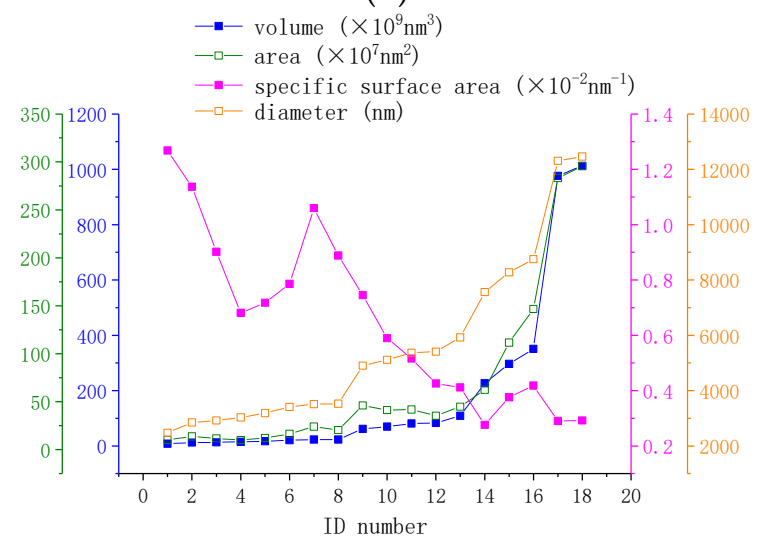

Figure 2. 3D image and quantitative analysis of anhydrous particles: (a) labeled 3D images of anhydrous particles and (b) the volume, area, specific surface area and diameter analysis of anhydrous $\mathrm{C}_{3} \mathrm{~S}$ particles.

\subsubsection{Interface Structure between Anhydrous $C_{3} S$ Particles and Hydrates}

Figure 3a displays the labeled images and a corresponding 3D image of another region of the sample with higher resolution. The lateral ( $X$ and $Y$ ) pixel size of these data is $20 \mathrm{~nm}$. while the depth (Z) pixel size is $15 \mathrm{~nm}$. The interface between anhydrous $\mathrm{C}_{3} S$ particles in light blue and hydrates in dark blue is relatively brittle compared with the matrix, but it is of great importance. Although SBFSEM technology is a destructive method, the interface between anhydrous particles and hydrates can be characterized clearly, as shown in Figure 3 a where the cutting thickness is $15 \mathrm{~nm}$. The inner hydrate layer surrounding anhydrous $C_{3} S$ particles and outer hydrates in the space between anhydrous $C_{3} S$ particles can be clearly seen.

As we can see in Figure 3a, two anhydrous particles are separated from each other along with the surrounding hydration products in Slice 1 . The hydrated products of the two anhydrous particles start to become connected in Slice 92 and are totally connected in Slice 180. The two anhydrous particles themselves begin to join together in Slice 279 and come to form a whole particle in Slice 281. The 3D image of this region shows that the two anhydrous $C_{3} S$ particles presented in Figure 3a, Slice 1, are in fact part of a single curved particle in Figure 3b. It would be easy to come to the wrong conclusion if we had analyzed the structure with just one 2D BSE image like Slice 1. Figure 3 illustrates the advantage of SBFSEM over 2D BSE image technology in the accuracy of characterization of phase morphology. 
In conclusion, SBFSEM can reveal the 3D characteristics of the morphology, which play an important role in revealing the relationship between the microstructure and performance of materials.

(a)

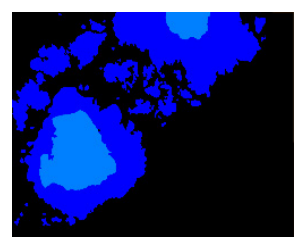

Slice 1

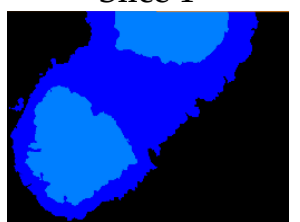

Slice 180

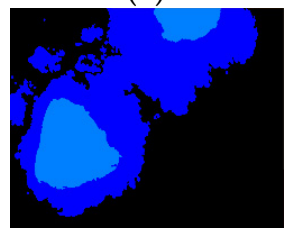

Slice 92

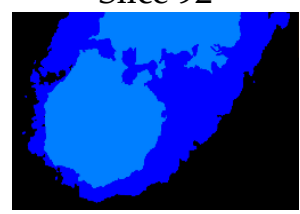

Slice 276

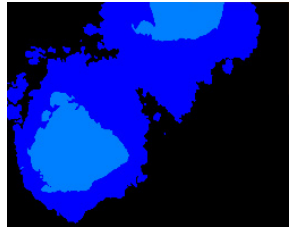

Slice 116

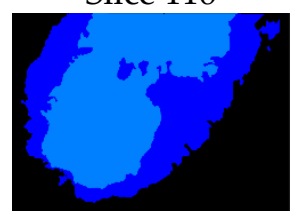

Slice 281 (b)

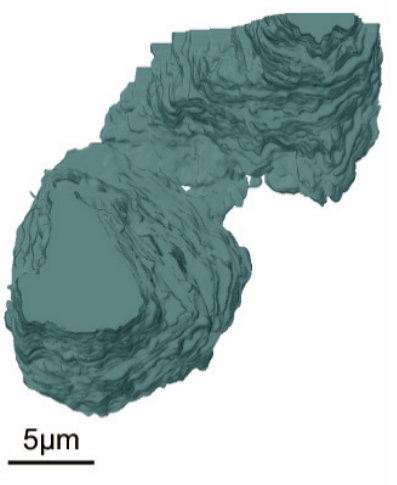

$\underline{5 \mu \mathrm{m}}$

Figure 3. Labeled images and $3 \mathrm{D}$ image of hydrated $\mathrm{C}_{3} S$ : (a) labeled images of numbered slices and (b) 3D image of an anhydrous particle.

\subsection{Analysis of Pore Structure in the Hydrated $C_{3} S$ Paste}

\subsubsection{Quantitative Analysis of Pores}

Pores are one of the most important microstructure characteristics of cement paste. Figure $4 \mathrm{a}$ demonstrates the 3D pore network in the hydrates of Figure 1. There are 4800 pores altogether. The large pore cluster rendered in green is a connected pore, which was separated from the other pores through the "axis connective" module (parameter setting: $z$-axis; pixel $>26$ ). The porosity of connected pores is related to the water transportation ability of the material, which will affect the further hydration of anhydrous $\mathrm{C}_{3} \mathrm{~S}$ particles. The porosity of the sample was about $9 \%$, of which connected porosity comprised $4.45 \%$. The pore volume, specific surface area, and pore diameter were analyzed quantitatively with results listed in Supplementary Spreadsheet S2. The volume of pores ranged from $1.2 \times 10^{6}$ to $2.0 \times 10^{11} \mathrm{~nm}^{3}$. The pore diameter ranged from 200 to $15000 \mathrm{~nm}$, and $99 \%$ of pore diameters were below $2000 \mathrm{~nm}$.

The lognormal distribution of pore volume and the frequency distribution of pore diameter $(<2000 \mathrm{~nm})$ are listed in Supplementary Spreadsheet S2 and shown in Figure 4b,c. The average pore volume was $1.7 \times 10^{7} \mathrm{~nm}^{3}$. The $95 \%$ confidence interval of the volume logarithmic distribution was $(7.224,7.260)$ which means $95 \%$ particles are between $1.6 \times 10^{7}$ and $1.8 \times 10^{7} \mathrm{~nm}^{3}$. The average diameter of pores was $380 \mathrm{~nm}$. According to Ma et al.'s study [10], pores in concrete can be classified into gel pores ranging from 0.5 to $10 \mathrm{~nm}$, capillary pores ranging from $10 \mathrm{~nm}$ to $10 \mathrm{um}$, and macropores above $10 \mathrm{um}$. As shown in Figure 4b, nearly all pores in the sample were capillary pores. No macropores were detected. The size of the gel pore is lower than the spatial resolution of SBFSEM and therefore cannot be identified.

The assessment of pores in cement paste has been studied for several decades. Mercury intrusion porosimetry (MIP) is the widely accepted method to measure open pores ranging from $1 \mathrm{~nm}$ to $1000 \mu \mathrm{m}$. Although the pore size range that SBFSEM can detect in our study is smaller than that of MIP, it still has great advantage in the study of the capillary pore structure of cement-based materials. Compared with MIP, SBFSEM can obtain not only the size distribution but also morphology and connectivity parameters of both open pores and closed pores. Since capillary pores play an important role in the strength, permeability, and shrinkage properties of hardened cement paste, accurate characterization of them is of great practical significance. From the MIP results of former literature, the porosities of typical cement materials are between $10 \%$ and $40 \%$ [46], but the porosity of our sample is about $9 \%$. Although the porosity seen by SBFSEM is in the range of $10-40 \%$, this apparent agreement is 
coincidental in consideration of the different pore types that the two methods can detect. While MIP can detect gel pores, capillary pores, and macropores, SBFSEM can detect both closed and open pores. Based on the imaging quality of SBFSEM in our study, influenced by the weak conductivity of samples and the cutting thickness along the z-axis, the spatial resolution of the images in three dimensions is around $50 \mathrm{~nm}$.

(a)

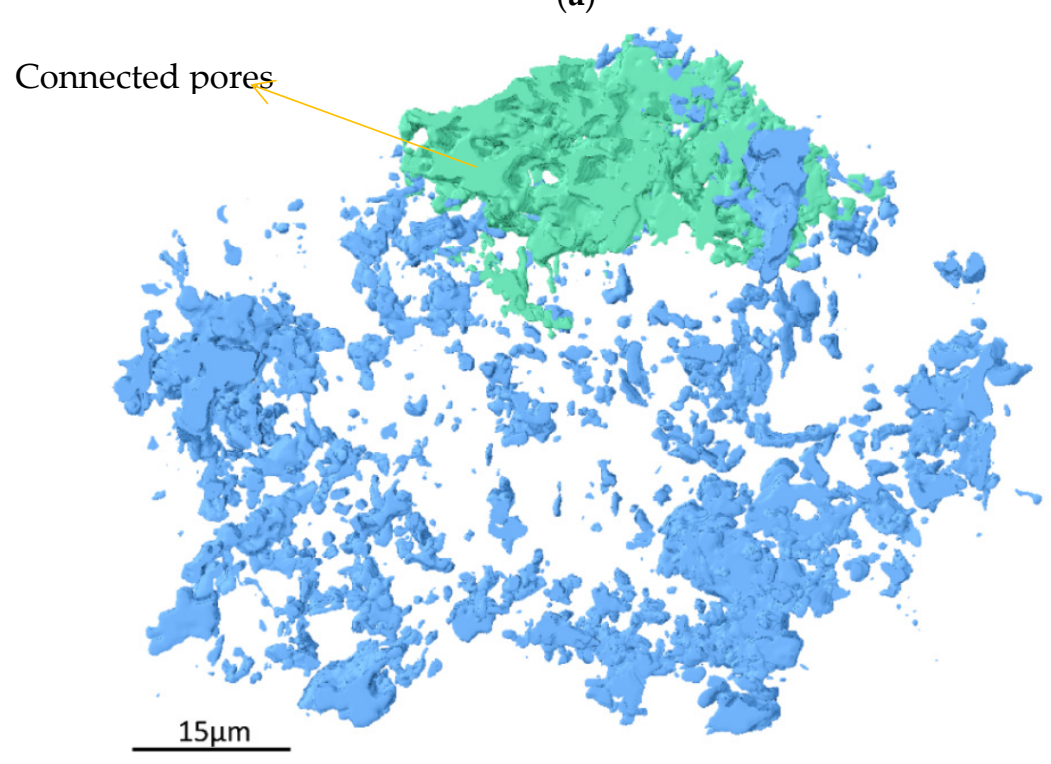

(b)

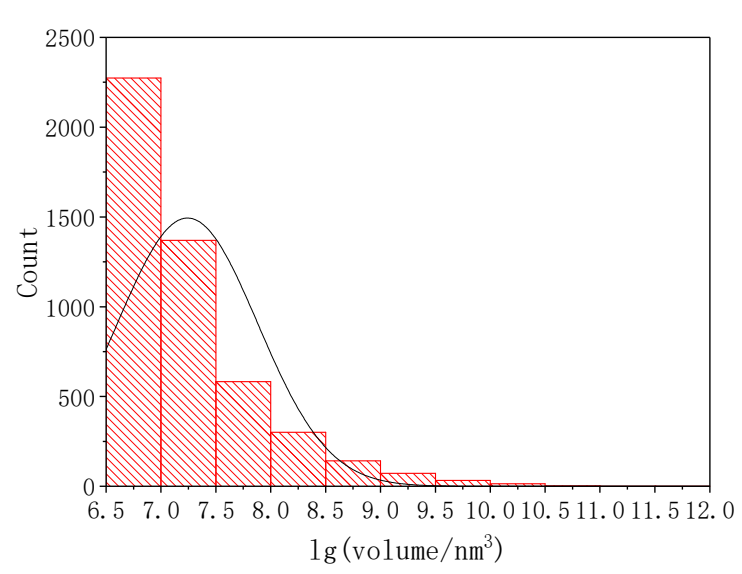

(c)

Figure 4. 3D image and analysis of pores: (a) 3D image of connected pores rendered in green and non-connective pores rendered in blue, (b) the volume distribution of all pores, and (c) the diameter distribution of all pores.

\subsubsection{The Spatial Distribution of Pores}

Additional pores were found to be located in the anhydrous particle of No. 17 (labeled in Figure 2a). These are believed to occur by sublimation during the solid phase sintering and are displayed in Figure 5. Figure 5 a presents the closed pore, while in Figure $5 b$, the anhydrous particles, hydrates and open pores in the anhydrous particle are displayed separately in transparent gray, blue, and purple colors. The pore located next to the boundary of the anhydrous particle is mostly surrounded by hydrates, and hydrates can also be viewed within a certain thickness of the inner wall of the pore. This arrangement suggests that the pore is more like an open pore than a closed pore. 
Open pores have an important relationship with water transportation and hence with hydration. Given that hydrates lie at the inner wall of the pore rather than filling the whole pore, this suggests that the open pore may have originated as closed pore (filled with air) in the anhydrous $C_{3} S$ particle. During hydration, this closed pore opened and the hydration reaction started at the interface between pores and hydrates and then gradually deposited around the inside of the pore.

(a)
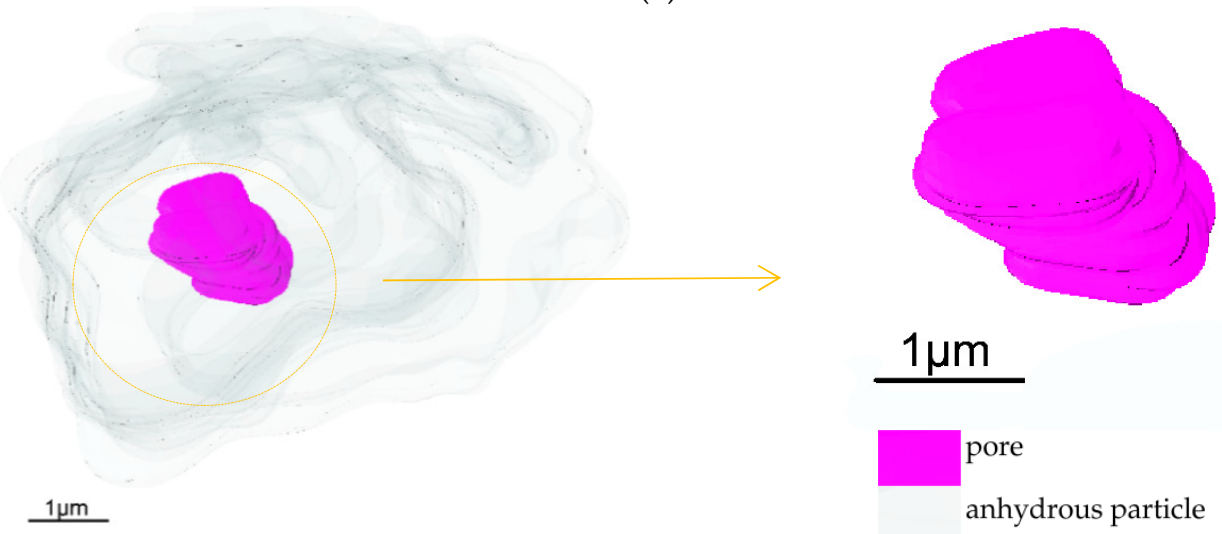

(b)
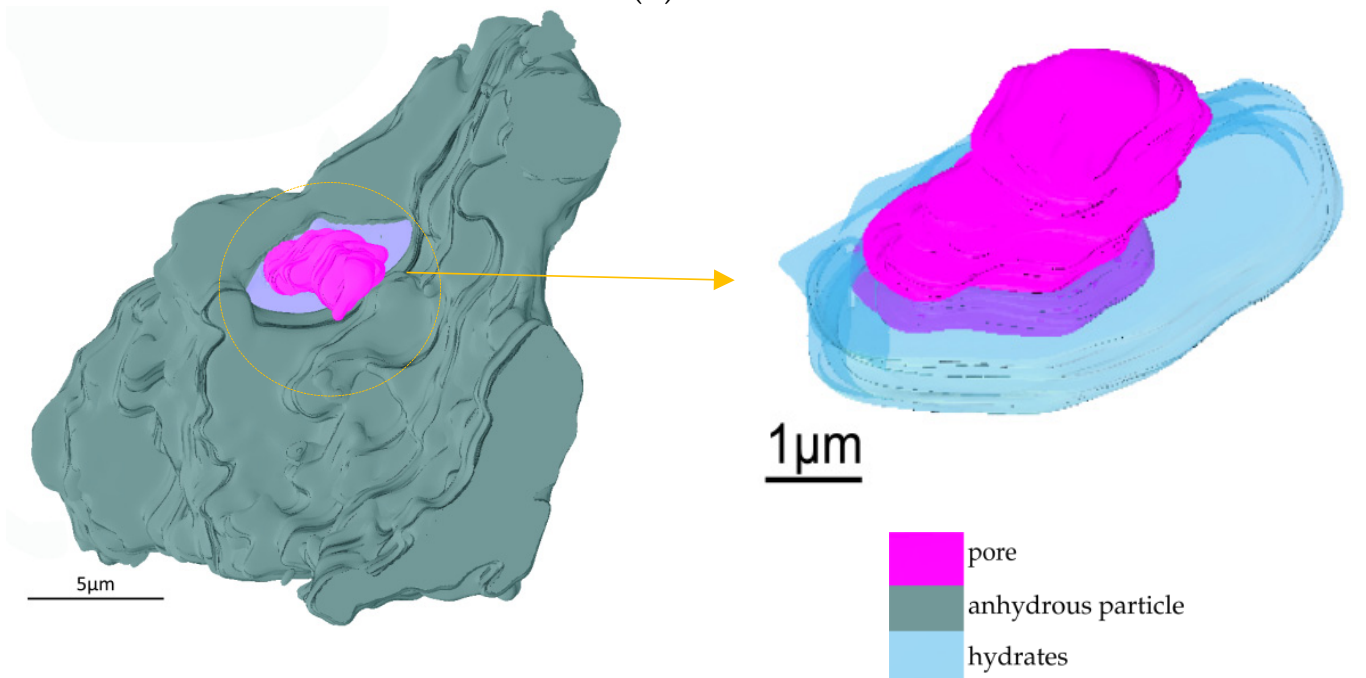

Figure 5. Two types pores in the anhydrous $C_{3} S$ particles: (a) closed pores and (b) open pores.

The distance from the capillary pores to the surface of the anhydrous particle was computed through the "surface distance" module in the Avizo software, which calculates the distance from each voxel on surface 1 to each voxel on surface 2 . To assist the distance computation, a small anhydrous particle, No. 2 in Figure 2a, was chosen and then the image was cropped into a $15 \times 14 \times 5.7 \mu \mathrm{m}$ region. Results are displayed in Figure 6 and Table 1, as well as in Supplementary Spreadsheet S3. In Figure 6 the pore network around the anhydrous particles is visualized using the shade of color to represent the distance from the anhydrous particle. The shortest distance between the pores and the anhydrous particles is $30 \mathrm{~nm}$, and the mean value is $4400 \mathrm{~nm}$ (Table 1). Distances below $860 \mathrm{~nm}$ make up only $0.4 \%$ of all pixels which means that almost all capillary pores are located more than $860 \mathrm{~nm}$ away from the anhydrous particle. According to Hu et al.'s study [2], the hydration products can be divided into inner hydration products (IP) with high density and outer hydration products (OP) with low density. Figure 1a clearly shows the difference in pore structure between IP and OP in the BSE image. Capillary pores tend to be found in the OP rather than IP. The demarcation between the IP and $\mathrm{OP}$ of the anhydrous particle can be better identified using the spatial distribution of capillary pores [47], even though they are difficult to distinguish through gray levels. From the above analysis, 
the thickness of IP is $860 \mathrm{~nm}$, and the OP starts from $860 \mathrm{~nm}$ and is further away. This analysis method can be used to identify the IP and OP using SBFSEM quantitatively. This new information will be of benefit to the research on 3D microstructure evolution during cement hydration and hence improve our knowledge of the hydration mechanism.

(a)

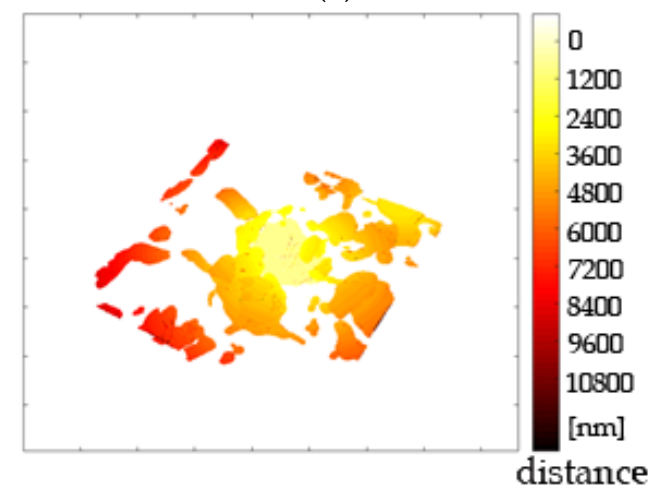

(b)

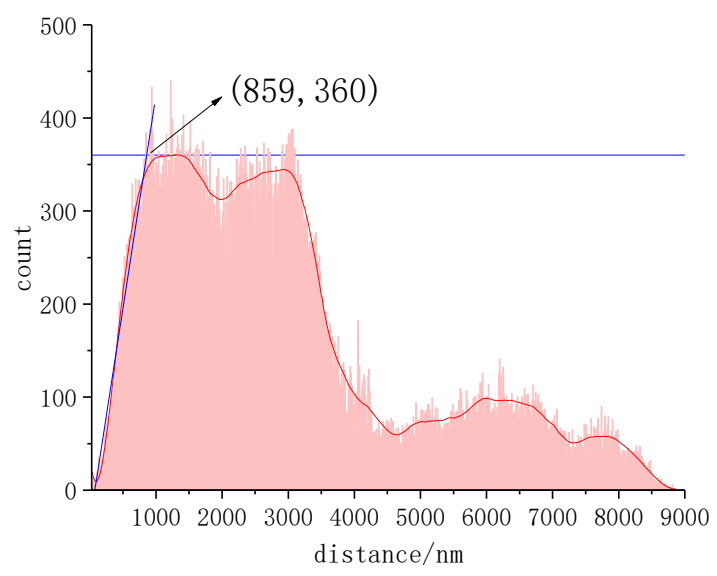

Figure 6. Distance of capillary pores from the surface of the anhydrous $C_{3} S$ particle qualitatively (a) and quantitatively displayed (b).

Table 1. The critical distance from pores to anhydrous particles.

\begin{tabular}{ccccc}
\hline & Min & Mean & Max & Inflexion \\
\hline Distance/nm & 30 & 4400 & 9000 & 860 \\
\hline
\end{tabular}

\section{Conclusions}

A recently-developed 3D electron microscopy technique, SBFSEM, was successfully applied to characterize the 3D microstructure of a cement monomineral, $\mathrm{C}_{3} \mathrm{~S}$, which is a brittle, hard, and porous inorganic material, after hydration for $24 \mathrm{~h}$. Due to the poor conductivity of inorganic material, the spatial resolution in this study was about $50 \mathrm{~nm}$ which made it possible to observe the 3D spatial structure of materials at the nanoscale. The morphology, size and distribution of anhydrous particles, hydrates, and pores were analyzed quantitatively. The volume of anhydrous $\mathrm{C}_{3} \mathrm{~S}$ particles ranged from $1.26 \times 10^{6}$ to $1.3 \times 10^{9} \mathrm{~nm}^{3}$. The diameter of the anhydrous particles ranged from 2500 to $12500 \mathrm{~nm}$. The above results are important for the study of hydration kinetics of $C_{3} S$ particles. The volume of pores ranged from $1.6 \times 10^{7}$ to $1.8 \times 10^{7} \mathrm{~nm}^{3}$ and their diameters ranged from 200 to $15000 \mathrm{~nm}$. The average pore volume and diameter were $1.7 \times 10^{7} \mathrm{~nm}^{3}$ and $380 \mathrm{~nm}$. The locations of open and closed pores associated with hydrates were found $860 \mathrm{~nm}$ away from the anhydrous particles. SBFSEM can be further applied to characterize the evolution of 3D microstructure of hardened cement paste at nanoscale. The 3D analytical results will help us to understand the cement hydration mechanism.

Supplementary Materials: The following supplementary materials are available online at http://www.mdpi.com/ 1996-1944/12/12/1882/s1, Spreadsheet S1: volume, area, specific surface area, and diameter of 18 anhydrous $C_{3} S$ particles in Figure 2a; Spreadsheet S2: volume, specific surface area, and diameter of pores below $2000 \mathrm{~nm}$ in Figure 4a; Spreadsheet S3: distance of capillary pores from the surface of the anhydrous $C_{3} S$ particle in Figure $6 a$.

Author Contributions: X.L., B.C. and I.R. conceived the project. Y.Z. (Yongjuan Zhao), X.L., Y.Z. (Yongming Zhang) and P.W. synthesized the $\mathrm{C}_{3} \mathrm{~S}$ monomineral. Y.Z. (Yongjuan Zhao) prepared the hydrated $\mathrm{C}_{3} \mathrm{~S}$ sample and carried out the SBFSEM experiment. Y.Z. (Yongjuan Zhao), F.Y. and B.C. prepared the epoxy embedded $C_{3} S$ sample to be measured with SBFSEM. Y.Z. (Yongjuan Zhao) and X.L. analyzed the data. Y.Z. (Yongjuan Zhao), X.L. and I.R. wrote the manuscript with contributions from all the other authors.

Funding: This research was supported by the Talent Program "Materials Nano-structure" (Grant No. 190073) at Tongji University, the National Natural Science Foundation of China (Grant No. 51102181), the Joint Funds of the National Natural Science Foundation of China (Grant No.U1534207) and the PuJiang Talent Program (Grant No. 
18PJ1410400). Work at Brookhaven National Laboratory was supported by the U.S. Department of Energy, Office of Science, Office of Basic Energy Sciences, under Contract No. DE-SC0012704. Work at UCL was supported by grant BB/H022597/1 from the BBSRC.

Acknowledgments: The SBFSEM measurements were carried out at the School of Materials Science and Engineering, Tongji University, China.

Conflicts of Interest: The authors declare no conflict of interest.

\section{References}

1. Richardson, I. Cement Chemistry, 3rd ed.; ICE Publishing: London, UK, 2018.

2. Hu, Q.; Aboustait, M.; Kim, T.; Ley, M.T.; Bullard, J.W.; Scherer, G.; Hanan, J.C.; Rose, V.; Winarski, R.; Gelb, J. Direct measurements of $3 \mathrm{~d}$ structure, chemistry and mass density during the induction period of $\mathrm{C}_{3} \mathrm{~S}$ hydration. Cem. Concr. Res. 2016, 89, 14-26. [CrossRef] [PubMed]

3. Taylor, H.F.W.; Barret, P.; Brown, P.W.; Double, D.D.; Frohnsdorff, G.; Johansen, V.; Ménétrier-Sorrentino, D.; Odler, I.; Parrott, L.J.; Pommersheim, J.M.; et al. The hydration of tricalcium silicate. Mater. Struct. 1984, 17, 457-468. [CrossRef]

4. Bullard, J.W.; Jennings, H.M.; Livingston, R.A.; Nonat, A.; Scherer, G.W.; Schweitzer, J.S.; Scrivener, K.L.; Thomas, J.J. Mechanisms of cement hydration. Cem. Concr. Res. 2011, 41, 1208-1223. [CrossRef]

5. Stark, J. Recent advances in the field of cement hydration and microstructure analysis. Cem. Concr. Res. 2011, 41, 666-678. [CrossRef]

6. Scrivener, K.L.; Nonat, A. Hydration of cementitious materials, present and future. Cem. Concr. Res. 2011, 41, 651-665. [CrossRef]

7. Esteves, L.P. On the hydration of water-entrained cement-silica systems: Combined SEM, XRD and thermal analysis in cement pastes. Thermochim. Acta 2011, 518, 27-35. [CrossRef]

8. Feng, X.; Garboczi, E.J.; Bentz, D.P.; Stutzman, P.E.; Mason, T.O. Estimation of the degree of hydration of blended cement pastes by a scanning electron microscope point-counting procedure. Cem. Concr. Res. 2004, 34, 1787-1793. [CrossRef]

9. Franus, W.; Panek, R.; Wdowin, M. SEM Investigation of Microstructures in Hydration Products of Portland Cement. In 2nd International Multidisciplinary Microscopy and Microanalysis Congress; Polychroniadis, E.K., Oral, A.Y., Ozer, M., Eds.; Springer International Publishing: Cham, Denmark, 2015; pp. 105-112.

10. Igarashi, S.; Kawamura, M.; Watanabe, A. Analysis of cement pastes and mortars by a combination of backscatter-based SEM image analysis and calculations based on the Powers model. Cem. Concr. Compos. 2004, 26, 977-985. [CrossRef]

11. Ylmén, R.; Jäglid, U.; Steenari, B.-M.; Panas, I. Early hydration and setting of Portland cement monitored by IR, SEM and Vicat techniques. Cem. Concr. Res. 2009, 39, 433-439. [CrossRef]

12. Groves, G.W. TEM Studies of Cement Hydration. Symp. M Microstruct. Dev. Hydration Cem. 2011, 85, 3. [CrossRef]

13. Richardson, I.G.; Skibsted, J.; Black, L.; Kirkpatrick, R.J. Characterisation of cement hydrate phases by TEM, NMR and Raman spectroscopy. Adv. Cem. Res. 2010, 22, 233-248. [CrossRef]

14. Han, S.; Yan, P.; Liu, R. Study on the hydration product of cement in early age using TEM. Sci. China Technol. Sci. 2012, 55, 2284-2290. [CrossRef]

15. Papadakis, V.G.; Pedersen, E.J.; Lindgreen, H. An AFM-SEM investigation of the effect of silica fume and fly ash on cement paste microstructure. J. Mater. Sci. 1999, 34, 683-690. [CrossRef]

16. Peled, A.; Castro, J.; Weiss, W.J. Atomic force and lateral force microscopy (AFM and LFM) examinations of cement and cement hydration products. Cem. Concr. Compos. 2013, 36, 48-55. [CrossRef]

17. Chotard, T.J.; Boncoeur-Martel, M.P.; Smith, A.; Dupuy, J.P.; Gault, C. Application of X-ray computed tomography to characterise the early hydration of calcium aluminate cement. Cem. Concr. Compos. 2003, 25, 145-152. [CrossRef]

18. Hu, Q.; Aboustait, M.; Kim, T.; Ley, M.T.; Hanan, J.C.; Bullard, J.; Winarski, R.; Rose, V. Direct three-dimensional observation of the microstructure and chemistry of $C_{3}$ S hydration. Cem. Concr. Res. 2016, 88, 157-169. [CrossRef] [PubMed] 
19. Gastaldi, D.; Canonico, F.; Capelli, L.; Boccaleri, E.; Milanesio, M.; Palin, L.; Croce, G.; Marone, F.; Mader, K.; Stampanoni, M. In situ tomographic investigation on the early hydration behaviors of cementing systems. Constr. Build. Mater. 2012, 29, 284-290. [CrossRef]

20. Helfen, L.; Dehn, F.; Mikulík, P.; Baumbach, T. Three-dimensional imaging of cement microstructure evolution during hydration. Adv. Cem. Res. 2005, 17, 103-111. [CrossRef]

21. Liu, X.; Aranda, M.A.G.; Chen, B.; Wang, P.; Harder, R.; Robinson, I. In Situ Bragg Coherent Diffraction Imaging Study of a Cement Phase Microcrystal during Hydration. Cryst. Growth Des. 2015, 15, 3087-3091. [CrossRef]

22. Hesse, C.; Goetz-Neunhoeffer, F.; Neubauer, J. A new approach in quantitative in-situ XRD of cement pastes: Correlation of heat flow curves with early hydration reactions. Cem. Concr. Res. 2011, 41, 123-128. [CrossRef]

23. Mendes, A.; Gates, W.P.; Sanjayan, J.G.; Collins, F. NMR, XRD, IR and synchrotron NEXAFS spectroscopic studies of OPC and OPC/slag cement paste hydrates. Mater. Struct. 2011, 44, 1773-1791. [CrossRef]

24. Scrivener, K.L.; Füllmann, T.; Gallucci, E.; Walenta, G.; Bermejo, E. Quantitative study of Portland cement hydration by X-ray diffraction/Rietveld analysis and independent methods. Cem. Concr. Res. 2004, 34, 1541-1547. [CrossRef]

25. Soin, A.V.; Catalan, L.J.J.; Kinrade, S.D. A combined QXRD/TG method to quantify the phase composition of hydrated Portland cements. Cem. Concr. Res. 2013, 48, 17-24. [CrossRef]

26. Vedalakshmi, R.; Sundara Raj, A.; Srinivasan, S.; Ganesh Babu, K. Quantification of hydrated cement products of blended cements in low and medium strength concrete using TG and DTA technique. Thermochim. Acta 2003, 407, 49-60. [CrossRef]

27. Winslow, D.N.; Diamond, S. Specific Surface of Hardened Portland Cement Paste as Determined by Small-Angle X-Ray Scattering. J. Am. Ceram. Soc. 1974, 57, 193-197. [CrossRef]

28. Guryanov, A.M. Nanoscale investigation by small angle neutron scattering of modified Portland cement compositions. In XXIV R-S-P Seminar, Theoretical Foundation of Civil Engineering; Jemiolo, S., Gajewski, M., Krzeminski, M., Eds.; Elsevier Science: Amsterdam, The Netherlands, 2015; Volume 111, pp. 283-289.

29. Allen, A.J.; Thomas, J.J. Analysis of C-S-H gel and cement paste by small-angle neutron scattering. Cem. Concr. Res. 2007, 37, 319-324. [CrossRef]

30. Parisatto, M.; Dalconi, M.C.; Valentini, L.; Artioli, G.; Rack, A.; Tucoulou, R.; Cruciani, G.; Ferrari, G. Examining microstructural evolution of Portland cements by in-situ synchrotron micro-tomography. J. Mater. Sci. 2015, 50, 1805-1817. [CrossRef]

31. Cook, R.A.; Hover, K.C. Mercury porosimetry of cement-based materials and associated correction factors. Constr. Build. Mater. 1993, 7, 231-240. [CrossRef]

32. Zhang, Y.; Wu, B.; Zhou, J.; Ye, G.; Shui, Z. Pore structure of blended cement paste by means of pressurization $i$ depressurization cycling mercury intrusion porosimetry. In Proceedings of the 1st Ageing of Materials \& Structures Conference, Delft, The Netherlands, 26-28 May 2014.

33. Ibrahim, M.; Arockiaraj, J.; Amritanand, R.; Venkatesh, K.; David, K.S. Recurrent Lumbar Disc Herniation: Results of Revision Surgery and Assessment of Factors that May Affect the Outcome. A Non-Concurrent Prospective Study. Asian Spine J. 2015, 9, 728-736. [CrossRef]

34. Leighton, S.B. SEM images of block faces, cut by a miniature microtome within the SEM-A technical note. Scan. Electron. Microsc. 1981, 1981 Pt 2, 73-76.

35. Denk, W.; Horstmann, H. Serial Block-Face Scanning Electron Microscopy to Reconstruct Three-Dimensional Tissue Nanostructure. PLoS Biol. 2004, 2, e329. [CrossRef] [PubMed]

36. Zankel, A.; Kraus, B.; Poelt, P.; Schaffer, M.; Ingolic, E. Ultramicrotomy in the ESEM, a versatile method for materials and life sciences. J. Microsc. 2009, 233, 140-148. [CrossRef] [PubMed]

37. Carr, J.; Milhet, X.; Gadaud, P.; Boyer, S.A.E.; Thompson, G.E.; Lee, P. Quantitative characterization of porosity and determination of elastic modulus for sintered micro-silver joints. J. Mater. Process. Technol. 2015, 225, 19-23. [CrossRef]

38. Chen, B.; Guizar-Sicairos, M.; Xiong, G.; Shemilt, L.; Diaz, A.; Nutter, J.; Burdet, N.; Huo, S.; Mancuso, J.; Monteith, A.; et al. Three-Dimensional Structure Analysis and Percolation Properties of a Barrier Marine Coating. Sci. Rep. 2013, 3, 1177. [CrossRef] [PubMed]

39. Hashimoto, T.; Curioni, M.; Zhou, X.; Mancuso, J.; Skeldon, P.; Thompson, G.E. Investigation of dealloying by ultra-high-resolution nanotomography. Surf. Interface Anal. 2012, 45, 1548-1552. [CrossRef] 
40. Lu, J.; Chen, B.; Liu, X.; Yang, F.; Robinson, I.K. 3D microstructure reconstruction of casting aluminum alloy based on serial block-face scanning electron microscopy. J. Alloys Compd. 2019, 778, 721-730. [CrossRef]

41. Bai, X.; Chen, B.; Yang, F.; Liu, X.P.; Silva-Nunes, D.; Robinson, I. Three-dimensional imaging and analysis of the internal structure of SAPO-34 zeolite crystals. RSC Adv. 2018, 8, 33631-33636. [CrossRef]

42. Kubota, Y. New developments in electron microscopy for serial image acquisition of neuronal profiles. Microscopy 2015, 64, 27-36. [CrossRef]

43. Peddie, C.J.; Collinson, L.M. Exploring the third dimension: Volume electron microscopy comes of age. Micron 2014, 61, 9-19. [CrossRef]

44. Yang, F.; Liu, X.; Zhao, Y.; Zhang, Y.; Wang, P.; Robinson, I.; Chen, B. Investigation of Three-Dimensional Microstructure of Tricalcium Silicate $\left(\mathrm{C}_{3} \mathrm{~S}\right)$ by Electron Microscopy. Materials 2018, 11, 1110. [CrossRef]

45. De la Torre, A.G.; Aranda, M.A.G. Accuracy in Rietveld quantitative phase analysis of Portland cements. J. Appl. Crystallogr. 2003, 36, 1169-1176. [CrossRef]

46. Wang, Y.-S.; Dai, J.-G. X-ray computed tomography for pore-related characterization and simulation of cement mortar matrix. NDT E Int. 2017, 86, 28-35. [CrossRef]

47. Bullard, J.W.; Hagedorn, J.; Ley, M.T.; Hu, Q.; Griffin, W.; Terrill, J.E. A Critical Comparison of 3D Experiments and Simulations of Tricalcium Silicate Hydration. J. Am. Ceram. Soc. 2018, 101, 1453-1470. [CrossRef] [PubMed]

(C) 2019 by the authors. Licensee MDPI, Basel, Switzerland. This article is an open access article distributed under the terms and conditions of the Creative Commons Attribution (CC BY) license (http://creativecommons.org/licenses/by/4.0/). 